\title{
Asian Professional Discourse Communities: Pedagogical Focus on Speech Forms for Oral Performance
}

\author{
Michael Guest \\ University of Miyazaki, Miyazaki, Japan
}

\begin{abstract}
The aim of this paper is to introduce four areas of pedagogical importance for English for Specific Purposes (ESP), particularly in terms of training for oral performances. These are: 1) transitional phrases 2) opening / closing gambits 3) strategic competence in dynamic speech events and 4) academic and formulaic lexical phrases. These four areas were selected after comparing discrete features of both effective and less effective English performances by non-native Englishspeaking medical professionals observed at international medical conferences held in Asia. The results of this field study suggest that specialist terminology is not an area that demands explicit pedagogical addressing and that absolute formal accuracy in English speech is not a decisive factor in performance efficacy for professionals within the Asian region. The resulting suggestions should help ESP teachers prioritize lesson contents to enable learners to deliver more effective oral performances within their respective professional and academic discourse communities.
\end{abstract}

\section{Background}

Over the past two decades it has become increasingly widely accepted among ESP researchers that two of the salient features that distinguish ESP from General English are that 1) ESP pedagogy should be based upon perceived learner needs (Belcher 2004; Dudley-Evans \& St. John, 1998, Flowerdew, 2012;) and 2) ESP research should be particularly genre-driven (Hyland 2004; Paltridge 2001; Swales 1990). Syllabi and curricula based upon these two features form the basis of a sound ESP pedagogy. As Belcher (2009) and Paltridge (2009) have argued, ESP research and classroom pedagogy are fundamentally interwoven.

The pedagogical importance of an awareness of discursive modes in academic conference English and its central role in helping foster entry to, or participation in, a given professional discourse community is supported by Shalom (2002). Webber (2002) highlighted the importance of the strategic management of post-presentation discussion (and, like this paper, uses medical English as a model). Webber (2005) compared written medical research articles with a spoken conference corpus and noted how discourse markers in particular mark the interactive nature of the spoken versions. Mauranen (2012) also emphasized the need for explicit discourse markers and cohesion in real-time speech, as well as the importance of managing dynamic question and answer sessions. 
Rowley-Jolivet (2012) has noted functional features of spoken commentary in text slides in scientific conference presentations, noting in particular the distinct differences between the written text and the accompanying commentary. Heino, Tervonen, \& Tommola (2002) likewise emphasized the superstructural features needed to transform a research article into an effective verbal presentation. Thompson (2002) discussed the importance of creating a narrative flow in academic presentations as a manifestation of the interpersonal function of language. All of these studies parallel and support the concerns and emphases presented in this paper as well as indicate the need for a greater pedagogical response to meet the needs of academic conference speakers.

This current discussion reflects these basic considerations. A survey conducted with 56 doctors practicing in a Japanese university hospital (Guest, 2013) indicated that Japanese doctors considered their professional English priorities to be threefold: 1) to maintain international liaisons in medical practice and research, 2) to be able to both read and write for academic publications, and 3) to perform successfully at international medical conferences. In this paper, the third of these priorities, English performance at international medical conferences, has been used to serve as a benchmark for developing suggestions regarding pedagogical priorities for both practicing physicians and medical students. The purpose of this study is to identify those speech form features of effective presentations that can or should be later applied pedagogically.

Although the immediate research focus is limited to the field of medicine and the specific genre of conference English (which includes presentations, poster sessions, participation in symposia, and social interactions at related conference functions), it is believed that results obtained here can also easily be applied to other academic professions that prioritize performance at international conferences.

Furthermore, although the research focus was initially limited to a survey and interviews of Japanese doctors in order to address the cause and nature of performance anxieties (see Guest, 2013), it was subsequently expanded to include the conference performance features of other Asian, non-native English speaking physicians since 1) it was assumed that they faced many of the same difficulties that Japanese doctors faced, and 2) it might be determined to some extent if features were Japan-specific or more widely applicable to the East Asian region. Therefore, it is believed that the application of these research observations into ESP classroom pedagogy may have implications for the entire Asian region and not merely Japan.

\section{Methods}

In order to gather qualitative data, the researcher attended 147 presentations given by nonnative English speaking Asia-based medical professionals at five international medical conferences (three in Japan, one in South Korea, and one in Thailand). The researcher also observed 21 poster session discussions (6 of in which the researcher participated actively and made notes after), 13 debate-style symposia, and a small number of conference-related interactional functions. Of the 147 presentations attended, 88 were performed by Japanese speakers. The remaining 59 presenters came from South Korea (19), Thailand (10), Taiwan (9), China (8), Vietnam (8), and Indonesia (5), nations in which English holds no official status. The immediate research goal was to distinguish the salient characteristics of speech forms used by more effective performers from those of the less effective ones. During the static speech events (presentations, symposia) notes were taken by the researcher to initially grade (from 1 to 5 , with 1 representing poor and 5 being excellent) overall efficacy based primarily upon the following criteria: 
1) Was the speaker able to effectively communicate the points he / she was intending to convey? The inherent quality, innovation, or novelty of the scientific research was not the concern here. Only if the researcher was able to understand what the presenter intended to convey could it be considered effective. This did not mean that the researcher had to fully understand the internal mechanisms of the medical research being presented, but to understand cohesion and rhetorical moves, for example, that Result $X$ was being compared to Result $\mathrm{Y}$, adversatively, or that Procedures $\mathrm{A}$ and $\mathrm{B}$ exist in a causal, sequential relationship. This criterion corresponds to Lewis' (2003) notion of "retention" as being one of the four main indicators of presentation efficacy (the others being rapport, message, and words / images).

2) Did the performance hold the attention or interest of fellow professionals who comprised the audience? If a large number of audience members were sleeping, texting or viewing cell phones, perusing programs, or otherwise engaged in inattentive behavior, one could immediately assume the non-efficacy of the presentation. Since other factors could account for individual inattentiveness (such as mistaken topical expectations or suitability), it was the general audience response that was observed. This corresponds to Lewis' (2003) notion of presentation "rapport," referring to visible feedback that the audience provides.

3) Was the presenter able to successfully manage interactions in the follow-up question and answer sessions, the dynamic aspect of the presentation speech event? Were queries addressed and resolved? Was the Q\&A session robust and illuminating? These criteria were also applied to poster session management.

Although these criteria may be considered somewhat subjective, evaluating the efficacy of dynamic speech events by more "objective" means, is somewhat elusive. Rendle-Short (2006) noted that while academic presentations are essentially monologic, there remains an interactive relation with the collective audience who are "co-authors of talk-in-interaction" (p. 10) wherein the audience should be taking "a particular positional configuration" (p. 9) which includes "being attentive, yet not talking" (p. 9). Eliciting appropriate audience response, thus, may be considered an indicator of presentation efficacy, although it must be noted that Rendle-Short's focus was upon academic presentation analysis, and not evaluation.

During the various conference speech events, notes were taken to highlight the specific features that marked presentations, symposia, or poster session discussions as effective or less effective performances. After judgments were made regarding the relative efficacy of the speakers, speech forms and features common to both more and less effective performances were noted, and their frequencies tabulated. For example, if a particular conclusion section was judged to be highly effective, the researcher made note of any speech features that aided efficacy, such as impactful transitional phrases, the ability to elaborate on presentation slide details, and the ability to deploy succinct phrases suited to the medical discourse community. Likewise, the inability to do so among less effective performers was also duly noted.

Each of the items noted in the results section (below), or at least a slight formal variation thereof, was noted at least five times during the speech events of effective communicators, with at least three of the speakers originating from different first-language sources. The country of origin of each speaker was noted to rule out potential claims of first-language influence, as well as to mark the form as being common to the Asian region as a whole.

Since $90 \%$ of the presentations attended were parallel sessions in which attendees could choose from a large number of concurrent presentations divided into minute professional 
specialties, variables that are often used to measure presentation efficacy, such as suitability of topic to audience, were not addressed in this study. Nor were most kinetic features, such as the visual quality of the slides, body language, gestures, or facial expressions addressed, although it was noted that intonation was influenced by the choice of language forms. Therefore, the study did not attempt to represent a holistic overview or evaluation of oral presentation skills in general but rather centered upon the language forms employed by the speakers.

The resulting tabulations are not intended to represent a spoken corpus prepared for statistical analysis. Rather, common features and patterns, as opposed to specific tokens or utterances, have been noted for relative frequency. Thus, if the common speaking features of effective communicators are noted and categorized, it is believed that these may ultimately serve to inform future ESP pedagogy. This, then, forms the central purpose of both the original research and this paper.

\section{Results}

After compiling and itemizing all the handwritten notes taken from the international conference performances, the researcher was able to identify four speech components that regularly marked effective performances and negatively marked ineffective performances. Two further salient observations were also made regarding non-factors in terms of efficacy. Each of these is listed below in turn, including authentic samples and commonly noted illustrative speech patterns noted from the conferences. It should be noted that there were occasionally slight variations in the verbatim form (such as dropped articles or plurals), with the essential form presented below.

\section{Effective Usage of Transitional Phrases / Discourse Markers}

This first measure of efficacy pertains to presentations, symposia, and the management of poster sessions. It was noted that effective speakers utilized a wide range of transitional phrases in performance, with the phrase chosen suited to the function that the speaker wished to express. Among the most common effectively used transitional phrases and markers were:

Following this / that ...

Let me expand on that ...

Looking at this in more detail...

Getting back to our main point ...

Okay, so where does that leave us?

As for $\mathrm{x}$,

Additionally / furthermore,

What we learned / found out / don't understand is . . .

Less effective presenters relied almost wholly upon more general connectives, such as but, then, so, next, and and/also. These were often used as all-purpose connectors with little or no relation to the context in which they were deployed, and without consideration for the actual rhetorical functions implied by the terms.

The more transitional phrases were poorly chosen or appeared ill-considered the greater was the effect of dulling the impact of the speech, nullifying attempts to express cause-effect, elaboration, itemization, or sequential relationships. It was also noted that a lack of versatility in using transitional phrases also had a negative impact on the intonation of the speaker, resulting in a decreased usage of speech dynamics, such as varied pacing and altering the force or intensity of speech (determining the nature of this relationship is an area that suggests further 
research but is beyond the immediate scope of this paper).

Six further sub-categories of transitional phrases that were frequently noted as aiding communicative efficacy were identified. These were:

\section{Elaborating / emphasizing}

It is important to take note of / consider ... .

The most important point to consider is ...

What I'd particularly like to point out / emphasize is ...

\section{Clarifying / defining}

... that is,

... which means,

... such as $x$,

In brief,

Interestingly,

In particular,

Especially was negatively marked as being overused, often employed as a filler without regard to the relationship with the surrounding text, and often ineffective.

\section{Explaining methods}

While exposing $x$ / during exposure

For this reason...

The question here is ...

Initially,

By / in doing so,

Therefore, our aim was to $\mathrm{x}$.

We have followed this protocol.

We explored the $x$ hypothesis. What is the $x$ hypothesis?

So, how did we start / proceed?

\section{Explaining results}

Basically,

Despite,

To our surprise,

As a result,

Here are the indicators of $X$.

So what is the mechanism?

The first possible reason is $x$.

If $x$ then $y$.

Anyway was negatively marked as being overused and ineffective.

\section{Referencing (both anaphoric and cataphoric)}

As I said / mentioned earlier

As shown previously

If you recall / I earlier noted / said that ... 


\section{Advancing or proceeding to the following section \\ OK, let's move on to $\mathrm{x}$ \\ Consequently, \\ Subsequently,}

Next was negatively marked as being overused and ineffective.

\section{Speech Event Opening and Closing Gambits}

A second area that distinguished effective from less effective performers was the choices of both opening and closing gambits. Less effective performers tended to state their names and affiliations followed by simply reading the titles of their presentations as written on the slides or poster using very static, formalized formulas ("Good morning, My name is x. I work at y. My topic is z. Now I'll start."). Subsequent sections were typically introduced using only the title term of that particular section ("Methods." "Summary." "Conclusion.").

More effective presenters, on the other hand, tended to start with a brief greeting and acknowledgment of thanks. This acknowledgment was often followed by proceeding directly into the presentation topic. This was particularly true of the short presentation parallel sessions, which constituted over ninety percent of the total presentations performed at these conferences. Some common and effective examples noted were:

Thank you Mr. / Ms. Chairman and good morning / afternoon colleagues.

For two years now at $x$ hospital / university, we have been investigating ...

As you know ...

It is often believed that...

It is well-known that ...

Recently our institution introduced...

Beginning the speech event with a rhetorical research question or surprising conclusion also proved to be an effective strategy:

Why has there been an increase in the number of incidences of $x$ in recent years?

What is the difference between $x$ and $y$ ? More to the point, why are they different?

How should we approach the problem of $x$ ?

It may be that the main cause of $x$ is not $y$ but in fact $z$.

We have discovered a new relationship between $x$ and $y$.

When introducing research protocols or methods, the term methods was not always used by effective speakers. In the six noted effective examples listed below, only the first actually uses the term:

First, let me go over our research methods.

The purpose of this study was to ...

First of all we have / had to consider $\mathrm{x}$.

In order to find out why $x$ occurs,

We'll focus on the question why.

Because it is important to identify $x$, we ...

Effective speakers did not always provide formal outlines at the outset but rather tended to frame their emphases as follows: 
Today, I'd like to go over $\mathrm{x}$ and $\mathrm{y}$.

Today l'd like to focus upon $\mathrm{x}$.

Let me talk about $\mathrm{x}$.

This is how I will be proceeding today.

I'd like to share $x$ with you.

For the introduction of summaries and conclusions, personalized forms such as the following were used effectively in closing sections:

Before ending my presentation, l'd like to ...

This is the last slide so l'd like to conclude my talk by saying / noting . . .

In conclusion, we feel / believe ...

So here's a summary of our findings.

Utilizing terms other than summary and / or conclusion also marked effective performances:

These outcomes / objectives ...

The following rhetorical questions and cleft structures were also employed effectively in framing closing statements:

Okay. So, what have we discovered / learned?

So, the lesson we learned from this is ...

So, what we can conclude is ...

What I can say from my study is ...

So this is just one example of $x$.

\section{Deploying Strategic Competence in Dynamic Speech Events}

Question and answer sessions are one of the most anxiety-inducing aspects of any conference for professionals whose first language is not English (Guest, 2013). This pertains not only to the interactions typically occurring at the end of formal presentations, but also to the management of interactive poster sessions and open-forum symposia. It was observed that performers deemed less effective suffered the greatest number of total communicative breakdowns in such sessions as they were attempting to manage non-scripted, real-time English.

More effective speakers, it was noted, did not so much produce formulaic expressions as utilize those expressions to employ management strategies, a skill widely known as strategic competence. As it is expected that non-native English speakers might often have to resort to repair / negotiation, or deal with vague or imprecise language, the ability to deploy such strategies proved very effective. Five such strategic categories were identified.

\section{Clarification}

So what exactly is your question?

Could you summarize your point / question, please?

What exactly do you mean by $\mathrm{x}$ ?

Sorry, have I considered what? (when a single key word had not been understood)

So could you state your main point or question in one short sentence, please?

So, in short, you're asking / saying ...

If I understand your question correctly ... .

Do you mean $\mathrm{x}$ (or $\mathrm{y})$ ? 


\section{Avoidance}

If you contact me after I can give you more information.

If you'd like more detail I'd be happy to talk with you later.

Perhaps Professor $X$ can say something more about this.

Well, what do you think? (returning the question to the questioner)

Do you have any ideas / opinions on that?

\section{Thanking / appeasement}

Thank you for your comment. We'll certainly take that into consideration.

Thank you for your suggestion.

That's a very interesting point.

As you suggest...

That's a good question.

I'm glad you asked that question.

\section{Admission of fault or weakness}

Sorry, we didn't research that.

That's interesting. We hadn't thought of that.

That's true. We didn't consider that. Thank you.

\section{Reformulation / confirmation}

I mean ... (used as an elaborator)

What I am saying is $x$.

Let me explain this another way.

Have I answered / understood your question (correctly)?

\section{Formulaic Phrases Related to the Professional / Academic Discourse Community}

One feature that readily and consistently distinguished effective from less effective performers was the ability of the former to use formulaic chunks that, while not specifically medical terminology, are nonetheless indicative of academic and professional discourse, particularly in formal speech events. Such formulaic expressions are also hallmarks of written professional and academic discourse (Biber, 2009; Ellis, Simpson-Vlach, \& Maynard, 2008; Gledhill, 2011). These formulaic expressions were particularly frequent when the speakers were describing 1) methods, hypotheses and descriptions, and 2) results, discussions, summaries and conclusions. The examples that were frequently noted, listed below with the formulaic phrases underlined, occurred largely within two sections. 


\section{Formulaic expressions associated with methods, hypotheses, and descriptions}

In the initial trials we investigated $x$.

In order to determine $x$ we carried out / conducted $y$.

To prevent $x$ from occurring,

At the time of $x$,

By reducing the pressure on $y$,

$Z$ consists of $x$ factors and $y$ factors.

This is the most important factor in determining $x$.

The visual disturbance was localized.

Usually we expose the tumor within a range of $x$ (and $y$ ).

We performed a comparative analysis.

... induced by the distribution of $x$.

$X$ is characteristic of $y$.

Considering / given the complex state of the patient,

According to a number of risk factors,

This chart demonstrates that ...

The mechanism occurs as follows.

Formulaic expressions associated with results, discussion, summaries, and conclusions

There is a significant / slight degree of correlation between $x$ and $y$.

Our database also indicates the probability of $x$.

Perhaps the most important / significant factor is $\mathrm{x}$.

This excluded any other possible findings.

Essentially, there is no difference between these two groups in terms of outcomes,

Judging from $x$,

On the basis of $x$,

From this relationship, it can be estimated that,

There is insufficient evidence to say / regarding $x$.

$X$ produced no statistically significant difference.

$\ldots$ due to the prevalence of $x$.

A similar finding was observed in $x$.

$X$ is associated with $y$, particularly when $z$ occurs.

We found that $x$ was inversely correlated to $y$.

These findings suggest that $x . .$.

The data generated by $x$ indicates a high intake / incidence of $y$.

To prevent the recurrence of $x, y$ is effective.

$\mathrm{X}$ inhibited the production of $\mathrm{y}$.

... resulting in long/ short-term/ positive outcomes

If we follow up long-term, the chances of recurrence ... .

Post-operative findings indicated $x$.

A substantial number of $x$ 's were located.

\section{Spoken English Marked as an Asian Professional Lingua Franca}

One salient observation made was the lack of a distinct correlation between polished grammatical accuracy and actual performance efficacy. Performers deemed effective often used forms that would not be considered canonical or "correct" by formal Anglo-American standards of English, but this in no way impeded the speaker's ability to convey meaning.

Below are several such collected examples, with an archetypical utterance displayed on the left and the canonical form indicated in parentheses on the right. Each of these patterns was 
uttered by a minimum of five effective presenters, presenters who one could deem fluent in English, and who originated from at least three different first-language backgrounds (again, to rule out the possibility of first language influence or interference). It is believed that the frequency with which these forms were uttered, and the fact that they had no negative impact on the conveyance of expression or meaning, may mark these as representative of English used as a non-standard, localized Asian English as a Lingua Franca (see, for example, Kirkpatrick, 2012).

Among the collected examples of possible ELF patterns were:

We placed (the) clamp on (the) $x$.

Three colonoscopy(ies) were performed during two separate period(s).

I'd like to show you some (a few) case(s).

We can well (easily / clearly) observe $x$.

There was so (a very) significant difference.

Why (The reason) we chose $\mathrm{x}$ is because ...

How to (can / should we do) $x$ ?

First, I (will) present $x$.

We want to ask why is this (this is) so.

How should we do (it)?

Next I (will) show you.

Even (though) we had prepared thoroughly.

Because of (there were) no symptom(s) . . .

It is not clear about the background of $x$. (The background of $x$ is not clear)

In (Using) this technique...

\section{Use of Specialist Terminology}

During the observations, almost no problematic issues involving the use of professional terminology in any of the speech events were noted. Even the performers marked as less effective displayed full control over the dense, narrow, medical terms used within their specialized research fields.

Evidently, the performers had acquired and absorbed this terminology at some earlier point, with previous research indicating that these items are acquired more as a result of immediate need and regular in-service usage within the specific field rather than prior explicit teaching in ESP classes (Guest, 2013; Wray, 2002) and not via explicit pre-teaching (Spack, 1988).

\section{Conclusions}

By comparing the speech form features of effective English-language performers with those of less effective ones at Asia-based international medical conferences, the researcher was able to identify four main areas in which a qualitative difference was salient. Less effective performers were held back by an apparently limited knowledge and / or deployment of transitional phrases, overly formalized and regimented opening and closing gambits, a lack of ability to manage breakdown and repair in open-ended interactions, and a lack of knowledge or ability to deploy formulaic chunks or set phrases common to the medical discourse community. It should once again be noted that this study focused upon presentation speech forms, and not the wider, more kinetic, aspects of oral presentations.

It was also noted that dense and narrow specialist terms did not pose difficulty for even the least effective performers, suggesting that these terms need not be considered a pedagogical priority for ESP teachers. Finally, it was noted that a number of surface "errors" did not impede the 
performance of many of the effective performers, but in fact marked their speech as being representative of a non-standard, Asian variety of English. However, it should be emphasized that acceptability of such forms would be limited only to the mode of speech and not written English.

The geographical limitations of this study beg the question as to what degree some of the problems and forms mentioned are Asia-specific or whether they are typical for any English as a second / foreign language learner. It also raises the question as to what degree, if any, the areas suggested in the research have already been incorporated into ESP teaching and learning. More specifically, the relationship between the choice of transition marker and resultant changes in intonation and pacing would benefit from a more detailed analysis.

\section{Implications for ESP Teachers}

Discovering the English learning needs of a target group, a hallmark of ESP teaching, can be achieved by looking at actual in-service performance, in this case by noting the presentation performance of physicians at international medical conferences. By comparing the relevant performance aspects of less effective and more effective performers, teachers can gain a sense of what aspects of performance for novice members of these professional and academic discourse communities need to be addressed or upgraded.

Based on the research observations and findings from this study, it is believed that ESP teachers should address these aspects of performance more thoroughly in Asian ESP classrooms, perhaps even explicitly including them in the course syllabus.

Although the professional interactions observed in this study all took place within medical conference contexts, there is no reason to believe that similar features and strategies would not be applicable to other Asian academic and professional discourse communities, particularly by practitioners from countries in which English does not hold any official status.

The findings also indicate that attaining complete accuracy according to Anglo-American standards of English should not be prioritized as a classroom goal, at least in terms of speech, and suggest that both teachers and learners in the region should be both aware and accepting of non-standard forms of English that reflect the innate capacity of the English language utilized across the region as a lingua franca.

\section{Author Note}

Michael Guest, Faculty of Medicine, University of Miyazaki, Miyazaki, Japan.

The original published research that provided background for this paper is: Guest, $M$. (2013). Japanese doctors at international conferences: Why the worry? Journal of Medical English Education, 12(3), 47-55.

This research was partially funded by a Grant-in-Aid for Scientific Research (Number 24652095) from the Japanese government.

Correspondence concerning this article should be addressed to Michael Guest, Faculty of Medicine, University of Miyazaki, 5200 Kihara, Oaza, Kiyotake-cho, Miyazaki Prefecture, Japan 889-1692. E-mail: mikeguest59@yahoo.ca 


\section{References}

Belcher, D. (2004). Trends in teaching English for Specific Purposes. Annual Review of Applied Linguistics, 24, 165-186. http://dx.doi.org/10.1017/S026719050400008X

Belcher, D. (2009). What ESP is and can be: An introduction. In D. Belcher (Ed.), English for Specific Purposes: Theory and practice (pp. 1-20). Ann Arbor: University of Michigan Press.

Biber, D. (2009). A corpus-driven approach to formulaic language in English: Multi-word patterns in speech and writing. International Journal of Corpus Linguistics, 14, 275-311. http://dx.doi.org/10.1075/ijcl.14.3.08bib

Dudley-Evans, T., \& St. John, M. (1998). Developments in English for Specific Purposes: A multi-disciplinary approach. Cambridge, U.K.: Cambridge University Press.

Ellis, N. C., Simpson-Vlach, R., \& Maynard, C. (2008). Formulaic language in native and second-language speakers: Psycholinguistics, corpus linguistics, and TESOL. TESOL Quarterly, 42(3), 375-396.

Flowerdew, L. (2012). Needs analysis and curriculum development in ESP. In B. Paltridge \& S. Starfield (Eds.), The handbook of English for Specific Purposes. Chichester, U.K.: John Wiley \& Sons.

Gledhill, C. (2011). The 'Lexicogrammar' approach to analysing phraseology and collocation in ESP Texts. La Revue de GERAS, 59, 5-23. http://dx.doi.org/10.4000/asp.2169

Guest, M. (2013). Japanese doctors at international conferences: Why the worry? Journal of Medical English Education, 12(3), 47-55.

Heino, A., Tervonen, E., \& Tommola, J. (2002). Metadiscourse in academic conference presentations. In E. Ventola, C. Shalom, \& S. Thompson (Eds.), The language of conferencing (pp. 127-146). Frankfurt, Germany: Peter Lang.

Hyland, K. (2004). Genre and second language writing. Ann Arbor, MI: University of Michigan Press.

Kirkpatrick, A. (2012). English as an Asian lingua franca: The 'Lingua Franca Approach' and its implications for language education policy. Journal of English as a Lingua Franca, 1(1), 1-13. http://dx.doi.org/10.1515/jelf-2012-0006

Lewis, G. B. (2003). Making effective scientific presentations. The Geological Society of America. Retrieved from http://www.geosociety.org/graphics/eo/Effective_Presentations.pdf

Mauranen, A. (2012). Exploring ELF: Academic English shaped by non-native speakers. Cambridge, U.K.: Cambridge University Press.

Paltridge, B. (2001). Genre and the language learning classroom. Ann Arbor, MI: University of Michigan Press.

Paltridge, B. (2009). Where have we come from and where are we now? In D. Belcher (Ed.), English for Specific Purposes: Theory and practice (pp. 289-296). Ann Arbor, MI: University of Michigan Press.

Rendle-Short, J. (2006). The academic presentation: Situated talk in action. Aldershot, U.K.: Ashgate Publishing.

Rowley-Jolivet, E. (2012). Oralising text slides in scientific conference presentations: A multimodal corpus analysis. In A. Boulton, S. Carter-Thomas, \& E. Rowley-Jolivet (Eds.), Corpus-informed research and learning in ESP: Issues and applications (pp. 135-166).

Shalom, C. (2002). The academic conference: A forum for enacting genre knowledge. In E. Ventola, C. Shalom, \& S. Thompson (Eds.), The language of conferencing (pp. 51-68). Frankfurt: Peter Lang.

Spack, R. (1988). Initiating ESL students into the academic discourse community: How far should we go? TESOL Quarterly, 22(1), 48-62. http://dx.doi.org/10.2307/3587060

Swales, J. M. (1990). Genre analysis. Cambridge, U.K.: Cambridge University Press. 
Thompson, S. (2002). 'As the story unfolds': The uses of narrative in research presentations. In E. Ventola, C. Shalom, \& S. Thompson (Eds.), The language of conferencing (pp. 147-168). Frankfurt: Peter Lang.

Webber, P. (2002). The paper is now open for discussion. In E. Ventola, C. Shalom, \& S.

Thompson (Eds.), The language of conferencing (pp. 247-254). Frankfurt: Peter Lang.

Webber, P. (2005). Interactive features in medical conference monologue. English for Specific

Purposes Journal, 24(2), 157-181. http://dx.doi.org/10.1016/j.esp.2004.02.003

Wray, A. (2002). Formulaic language and the lexicon. Cambridge, U.K.: Cambridge University Press. http://dx.doi.org/10.1017/CBO9780511519772 